\title{
CELL ADHESION, MORPHOLOGY AND BIOCHEMISTRY ON NANO- TOPOGRAPHIC OXIDIZED SILICON SURFACES
}

\author{
Chung-Yao Yang ${ }^{1}$, Lin-Ya Huang ${ }^{2}$, Tang-Long Shen ${ }^{2,3, *}$ and J. Andrew Yeh $^{1 *}$ \\ ${ }^{1}$ Institute of Nanoengineering and MicroSystems, National Tsing Hua University, Hsinchu 300, Taiwan, ROC \\ ${ }^{2}$ Department of Plant Pathology and Microbiology, ${ }^{3}$ Center for Biotechnology, National Taiwan University, Taipei \\ 106, Taiwan, ROC
}

\begin{abstract}
Manipulating an incorporated scaffold to direct cell behaviors play a key role in tissue engineering. In this study, we developed novel nano-topographic oxidized silicon nanosponges capable of being modified with various chemicals of a few $\mathrm{nm}$ in thickness to gain further insight into the fundamental biology of cell-environment interactions in vitro. A wet etching technique was applied to fabricate the silicon nanosponges in a high-throughput manner and was followed by vapor deposition of various organo-silane chemicals to enable self-assembly on the surfaces of the silicon nanosponges. When Chinese hamster ovary cells were cultured on these chemically modified nano-topographic structures, they displayed distinct morphogenesis, adherent responses, and biochemical properties in comparison with those of their planar oxidized silicon counterparts. There were predominant nano-actin punches and slender protrusions formed while cells were cultured on the nano-topographic structures, indicating that cell behaviors can be influenced by the physical characteristic derived from nano-topography, in addition to the hydrophobicity of contact surfaces. This study demonstrates potential applications of these nanotopographic biomaterials for controlling cell development in tissue engineering as well as in basic cell biology research.
\end{abstract}

Keywords: keywords: nanosponge; cell adhesion; cell morphology

*Addresses for correspondence:

J. Andrew Yeh

Institute of Nanoengineering and MicroSystems

National Tsing Hua University

No. 101, Sec. 2, Kuang-Fu Rd., Hsinchu 30013

Taiwan, ROC

Telephone Number: 886-(3)-571-5131 ext. 42912

FAX Number: 886-(3)-574-5454

E-mail: jayeh@mx.nthu.edu.tw

Prof. Tang-Long Shen

Department of Plant Pathology and Microbiology and Center for Biotechnology, National Taiwan University

No. 1, Sec. 4, Roosevelt Rd., Taipei 10617, Taiwan, ROC

Telephone number: 886-(2)-3366-4998

Fax number: 886-(2)-2363-6490

E-mail: shentl@ntu.edu.tw
Introduction

Cell to cell and cell to extracellular matrix (ECM) contacts are necessary for the in vivo formation of tissues and organs. Several molecular mechanisms by which cells perceive and respond to their surrounding environments have been studied, including integrin-ligand interactions (Chou et al., 1995; Neff et al., 1998; Keselowsky et al., 2004; Romanova et al., 2006; Pesen and Haviland, 2009), contact surface hydrophobicity (Van der Valk et al., 1983; Webb et al., 1998; Arima and Iwata, 2007) and ECM topography and architecture (Lee et al., 2002; Andersson et al., 2003; Dalby et al., 2003; Dalby et al., 2005; Sapelkin et al., 2006; Choi et al., 2007; Low et al., 2009; Qi et al., 2009). In particular, cell adhesion to the ECMs through integrin receptors has been reported to play a central role in numerous physiological and pathological processes. Given the importance of cell adhesive surfaces in bioengineering and biotechnology, the development of in vivo biomimetic scaffold materials suitable for enabling cell attachment and for supporting a desirable architecture has been widely studied (Langer and Vacanti, 1993; Singhvi et al., 1994). In fact, several inter-disciplinary collaborations between engineering and life sciences researchers have aimed at developing a biologically compatible scaffold. Typically, these scaffolding materials are comprised of biological and synthetic components that have been shown to enable modulating cellular responses in vitro. Accordingly, the in vitro control of the cellular environment is a major challenge for manipulating both cell development and scaffold substitute function in the field of bioengineering. However, the majority of in vitro studies in this field have utilized plastic or glass surfaces during cell culture, whose topographies are not found in nature. Noticeably, three-dimensional environments providing a surrounding support for cells in vivo had been shown critical for various physiological and pathological processes in numerous studies (Friedl et al., 1998; EvenRam and Yamada, 2005). Therefore, such differences existed in natural and experimental surface characteristics may confer, at least in part, some of the discrepancies reported between in vivo and in vitro results (Marks, 2005).

To resolve the discrepancies between in vivo and in vitro experiments, several approaches have been used to generate biomimetic in vitro environments. Those studies can be divided into the examination of cell interaction either with the substrate's topography (physical domain) or with the substrate's chemical nature (chemical domain). Within the chemical domain, studies of self assembled monolayers (SAMs) of alkanethiols have shown their 
capacity to affect the action potential of neurons (Romanova et al., 2006). Moreover, addition of various chemicals or proteins on selected areas also demonstrated that cell adhesion could be synergistically attributed by specific substrates and surface topographies (Neff et al., 1998; Pesen and Haviland, 2009). Concurrent with the above, studies on engineered fibronectin (FN) adsorption or conformation exhibited that either of which could regulate cell adhesion and gene expression independently and dependently (Chou et al., 1995; Keselowsky et al., 2004). As a result, numerous micro and nanoengineering approaches in combination with presenting specific chemical molecules on them have been used to manipulate in vitro cell-substrate interactions.

Nano-topography on engineered surfaces can affect protein adsorption, cytoskeletal arrangement, and cell adhesion as well as spreading (Graeter et al., 2007; Jungbauer et al., 2004). The effects of nano-topographic features on these cell behaviors have been investigated using a variety of nanoscale patterns, such as columns (Dalby et al., 2003; Dalby et al., 2005), sharp tips (Choi et al., 2007; Qi et al., 2009), pores (Sapelkin et al., 2006; Low et al., 2009), and dots (Lee et al., 2002; Andersson et al., 2003). To be noted, in nature, the topographic scale of adhesive protein molecules such as fibronectin, laminin, and collagen fibers is present on the order of $\mathrm{nm}$. Therefore, to biomimic cell adhesion and relative responses in an in vivo condition, cell adhesion surfaces are required to present biocompatible contact sites in a nanoscale dimension with periodicity. Nonetheless, the physical and/ or chemical nature of the interactions between the cell and the surfaces in controlling a specific cell behavior remains unclear.

To investigate cell behaviors on biocompatible and biomimetic conditions in a nanoscale manner, oxidized silicon nanosponge structures coated with different monolayers of functional groups were generated to examine cell responses, such as cell adhesion, organization of the cytoskeleton, and biochemical changes. Our results suggest that our nm-sized topographical biocompatible substrates potentially provide a distinct in vitro environment and thereby facilitating a better manipulation and understanding of cell behaviors that resemble those that occur in an in vivo environment.

\section{Materials and Methods}

\section{Surface treatment of oxidized silicon substrates and nanosponges}

Nanosponges were fabricated on monocrystalline silicon wafers using Ag-nanoparticles (AgNPs) assisted etching (Fig. 1a) (Peng et al., 2006; Chyan et al., 2009). The wafer was dipped into the $0.01 \mathrm{M}$ silver nitrate solution for $5 \mathrm{~min}$. Silver ions $\left(\mathrm{Ag}^{+}\right)$in the solution will reduce on the $\mathrm{Si}$ surface because electro negativity of Ag is higher than $\mathrm{Si}$. After formation of metallic catalyst layer, the wafer was immersed in the etchant comprising hydrogen fluoride (HF, $49 \% \mathrm{wt})$ and hydrogen peroxide $\left(\mathrm{H}_{2} \mathrm{O}_{2}, 30 \% \mathrm{wt}\right)$ with the mixture ratio of $3: 1(\mathrm{v} / \mathrm{v})$ for $3 \mathrm{~min}$. The formation mechanism of silicon nanosponges was previously described by Peng et al. (2006). Both the nanosponges and silicon wafers were oxidized to produce a $20 \mathrm{~nm}$ thick silicon dioxide layer atop for biocompatibility enrichment. The wafers were then diced into $1 \mathrm{~cm}^{2}$ pieces for the tissue culture wells. The organo-silane chemicals used for surface modifications included 3-aminopropyltrimethoxysilane (APTMS) with an amino group $\left(\mathrm{NH}_{2}\right)$ and perfluorodecyltrichlorosilane (FDTS) with fluorine (F). The above highly pure chemicals $(>96 \%)$ were obtained from Alfa Aesar (Ward Hill, MA, USA).

The surfaces of the wafers were hydroxylated by $\mathrm{O}_{2}$ plasma treatment for $10 \mathrm{~min}$ followed by the vapor deposition of silanol groups from the chemical precursors in the vacuum chamber (Fig. 1b). The reaction pressure can be controlled within a relatively wide range depending on the initial vapor pressure of the precursor used in the reaction but is typically maintained in the range of 0.1 to 50 Torr. A molecular layer was self-assembled on the surfaces by means of a silanol-hydroxyl reaction. The mechanism for the formation of molecular layer has been previously described by Kobrin et al. (2005). In this experiment, the vapor pressure of FDTS and APTMS was 2 and 2.5 Torr, respectively. The time required for the silanol-hydroxyl reaction of FDTS and APTMS reaction was 15 and $60 \mathrm{~min}$, respectively. Overall, six different substrates in combination with nano-topography and various chemical modifications were generated, including pristine oxidized silicon substrate, FDTS-coated oxidized silicon substrate, APTMS-coated oxidized silicon substrate, pristine oxidized silicon nanosponge, FDTScoated oxidized silicon nanosponge, and APTMS-coated oxidized silicon nanosponge.

\section{Surface hydrophobicity}

The surface hydrophobicity of the above substrates was characterized using contact angle measurement on a contact angle meter MD 100SB (Sindatek Instruments Co., Taiwan) with MagicDroplet V1.0d software. A droplet of deionized water (volume $=2 \mu \mathrm{l}$ ) was first placed on the substrates at room temperature, and then the sessile contact angle was determined to derive the hydrophobicity after the droplet was stabilized.

\section{Cell culture}

Chinese hamster ovary $(\mathrm{CHO})$ cells were cultured in normal tissue culture T25 flasks or in $100 \mathrm{~mm}$ plates (BD; Franklin Lakes, NJ, USA) with Ham's F-12 medium (Invitrogen Molecular Probes, Carlsbad, CA, USA) containing $10 \%$ fetal bovine serum (FBS; HyClone Laboratories Inc., Rockford, IL, USA) and supplemented with $1 \%$ glutamine, $1 \%$ penicillin, and $1 \%$ streptomycin at $37^{\circ} \mathrm{C}$ in a humidified $5 \% \mathrm{CO}_{2}$ incubator. Cells were trypsinized with trypsin-ethylenediaminetetraacetic acid (EDTA) and re-plated on the aforementioned substrates present in 6-well or 12-well culture plates for two hours to perform cell adhesion and fluorescent staining experiments as indicated. Steam sterilization of these substrates was undertaken prior to cell culture. 
a.

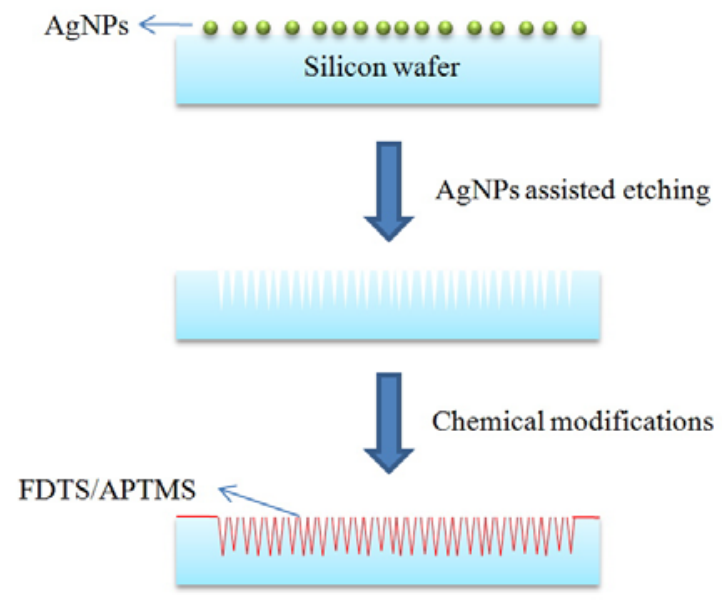

b.

Fig. 1. (A) Fabrication process of the substrates. Silicon nanosponges were formed by Ag nanoparticle-assisted etching. Different chemicals (FDTS/APTMS) were self-assembled on nanosponge structures by vapor deposition. (B) The mechanism of the self-assembled chemicals. Surface treatment began with $\mathrm{O}_{2}$ plasma treatment for surface hydroxylation, followed by vapor deposition of silanol groups from the chemical precursors. Finally, the reaction between silanol and hydroxyl occurred on the surface, and the monolayer was self-assembled on the surface.

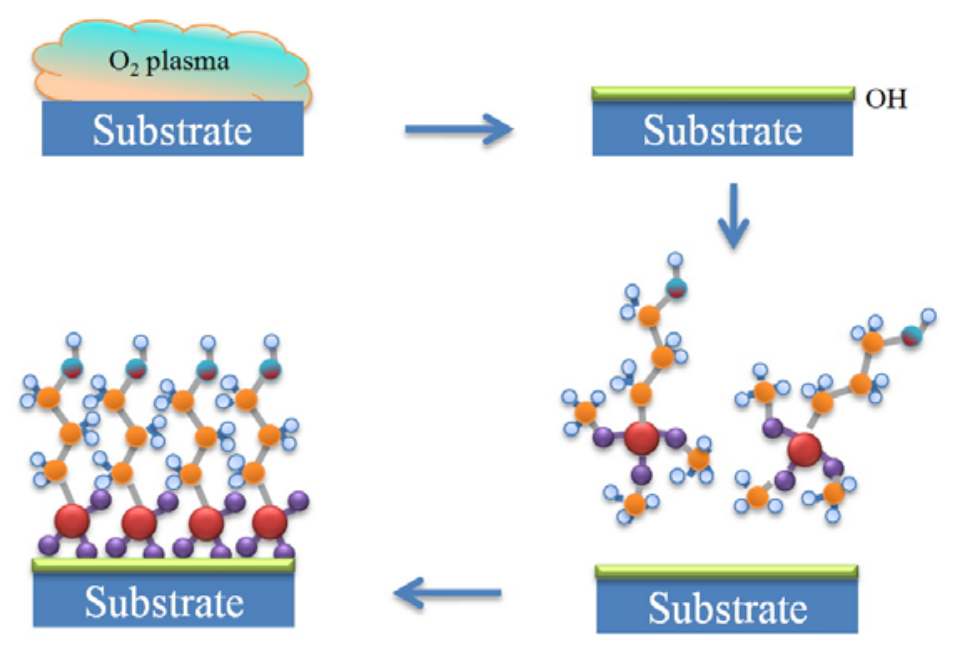

\section{Scanning electron microscopy}

The morphology of CHO cells adhered onto the aforementioned substrates was visualized with the scanning electron microscope (SEM) S-4300 (Hitachi, Tokyo, Japan). Briefly, the adhered cells were first fixed in a fixative containing $2.5 \%$ glutaraldehyde / $0.1 \mathrm{M}$ PBS at $4^{\circ} \mathrm{C}$ for $30 \mathrm{~min}$. After washing twice with $0.1 \mathrm{M} \mathrm{PBS}$, the cells were postfixed with $1 \%$ osmium tetroxide (SigmaAldrich; St. Louis, MO, USA) at room temperature for 30 min. The cells were then washed twice with PBS, dehydrated through serial gradients of ethanol (10 min for each gradient), and finally dried out by the critical point dryer HCP-2 (Hitachi). The cells along with the substrates were sputtered with gold at a current of $15 \mathrm{~mA}$ for $3 \mathrm{~min}$ by the ion sputter E-1010 (Hitachi). SEM imaging was conducted at voltages ranging from $5-10 \mathrm{kV}$.

\section{Laser scanning confocal microscopy (LSCM)}

Immunofluorescent staining was performed according to a previous description with a few modifications (Shen et al., 2005). Briefly, CHO cells were cultured on the aforementioned substrates for $2 \mathrm{~h}$, followed by two PBS washes. The cells were fixed with fresh $4 \%$ paraformaldehyde for $15 \mathrm{~min}$ at room temperature. After washing with PBS again, the substrates were immersed in $0.1 \%$ Triton X-100 in PBS for 10 min to permeabilize the cell membranes. Non-specific binding sites were blocked by incubation with $1 \%$ bovine serum albumin (BSA; Sigma-Aldrich) for $30 \mathrm{~min}$ at room temperature. Rhodamine-conjugated phalloidin (Invitrogen Molecular Probes) was used to stain the actin filaments, while 4',6diamidino-2-phenylindole (DAPI; Invitrogen Molecular Probes) was used to stain DNA in the nuclei. After mounting on glass cover slides, all fluorescence images were acquired with a laser scanning confocal microscope (Zeiss LSM 510 META, Göttingen, Germany) equipped with a 10X eyepiece and under a $100 \mathrm{X}$ oil (NA 1.4) objective lens.

\section{Cell adhesion assay}

A density of $5 \times 10^{5} \mathrm{CHO}$ cells $\mathrm{mL}^{-1}$ was seeded on the six different substrates for various adhesion time intervals (i.e., $30,60,120$, and 240 min for short periods; and 4, 24, 48, and $72 \mathrm{~h}$ for long periods). The substrates were washed 

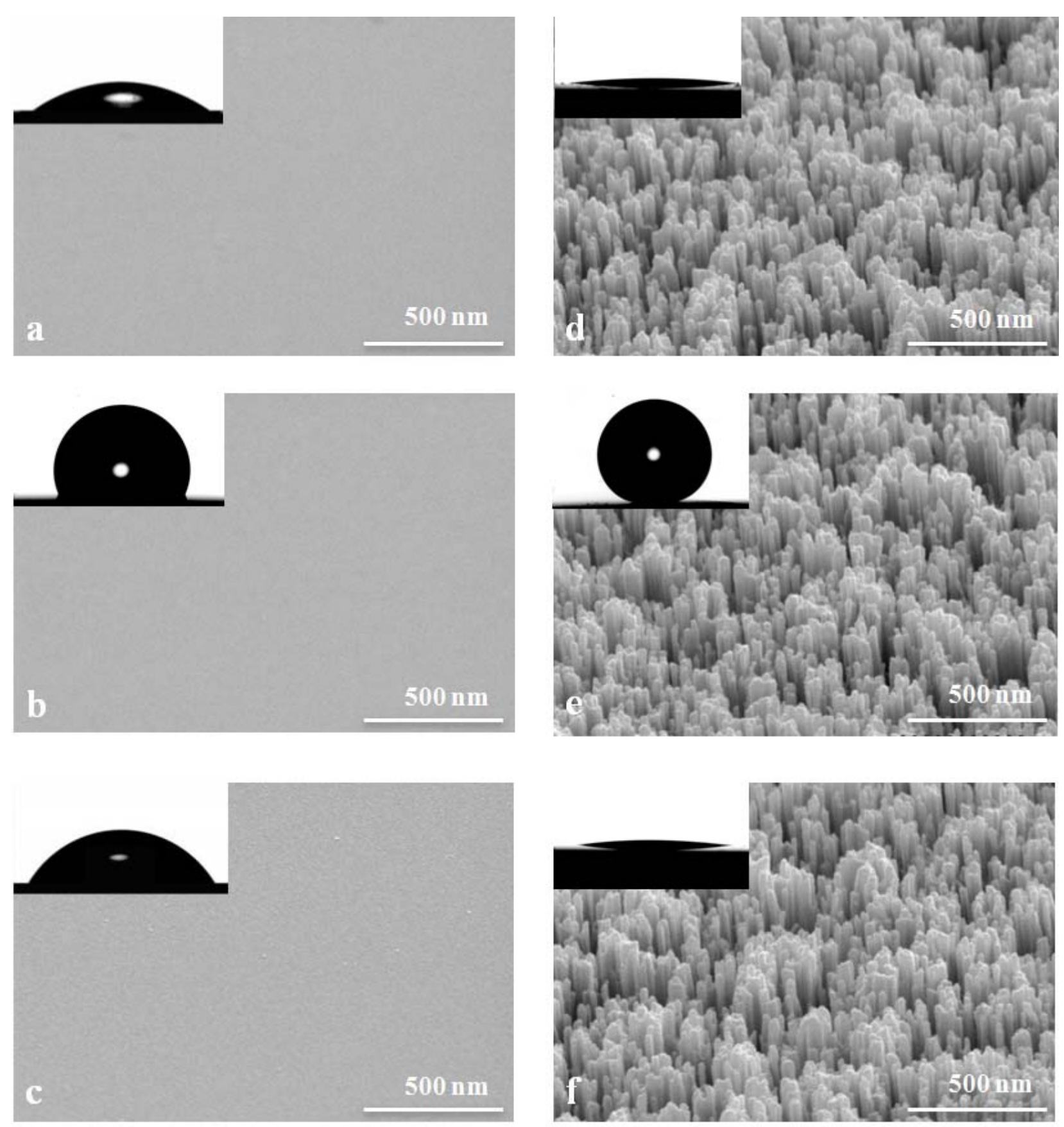

Fig. 2. SEM images and water contact angles of functionalized substrates: (A) Pristine oxidized silicon substrate; (B) FDTS-coated oxidized silicon substrate; (C) APTMS-coated oxidized silicon substrate; (D) Pristine oxidized silicon nanosponge; (E) FDTS-coated oxidized silicon nanosponges; (F) APTMS-coated oxidized silicon nanosponges.

twice with PBS after an interval of cell culture. The adhered cells were harvested with trypsin-EDTA, and the cell number was counted using a hemocytometer.

\section{MTS assay}

Approximately $3 \times 10^{5}$ cells were seeded on the indicated substrate chips (at a size of $1 \mathrm{~cm} \times 1 \mathrm{~cm}$ ) in each well of a 24-well culture plate. The cells were cultured with growing medium containing $10 \% \mathrm{FBS}$ at $37^{\circ} \mathrm{C}$ in a humidified, $5 \%$ $\mathrm{CO}_{2}$ atmosphere incubator. At the indicated time, the chips were washed by PBS for three times and were immersed in cultured medium with 20\% MTS (3-(4, 5dimethylthiazol-2-yl)-5-(3-carboxymethoxyphenyl)-2-(4sulfophenyl)-2H-tetrazolium; Promega, Madison WI). The reaction was conducted for $1 \mathrm{~h}$, and the absorbance of 490 $\mathrm{nm}$ was recorded. To obtain the viability of each cell, the total MTS was normalized by total cell number attached on the chip surface(s) to present the averaged MTS value of attached cells.

\section{Western blotting}

Cell lysates were collected after the CHO cells were replated for $2.5 \mathrm{~h}$ on the aforementioned substrates. Equal amounts of whole cell lysates were subjected to SDSPAGE, followed by western blot analyses using anti-FAK, anti-phospho-Tyr397, anti-phospho-925, and anti-actin antibodies. 

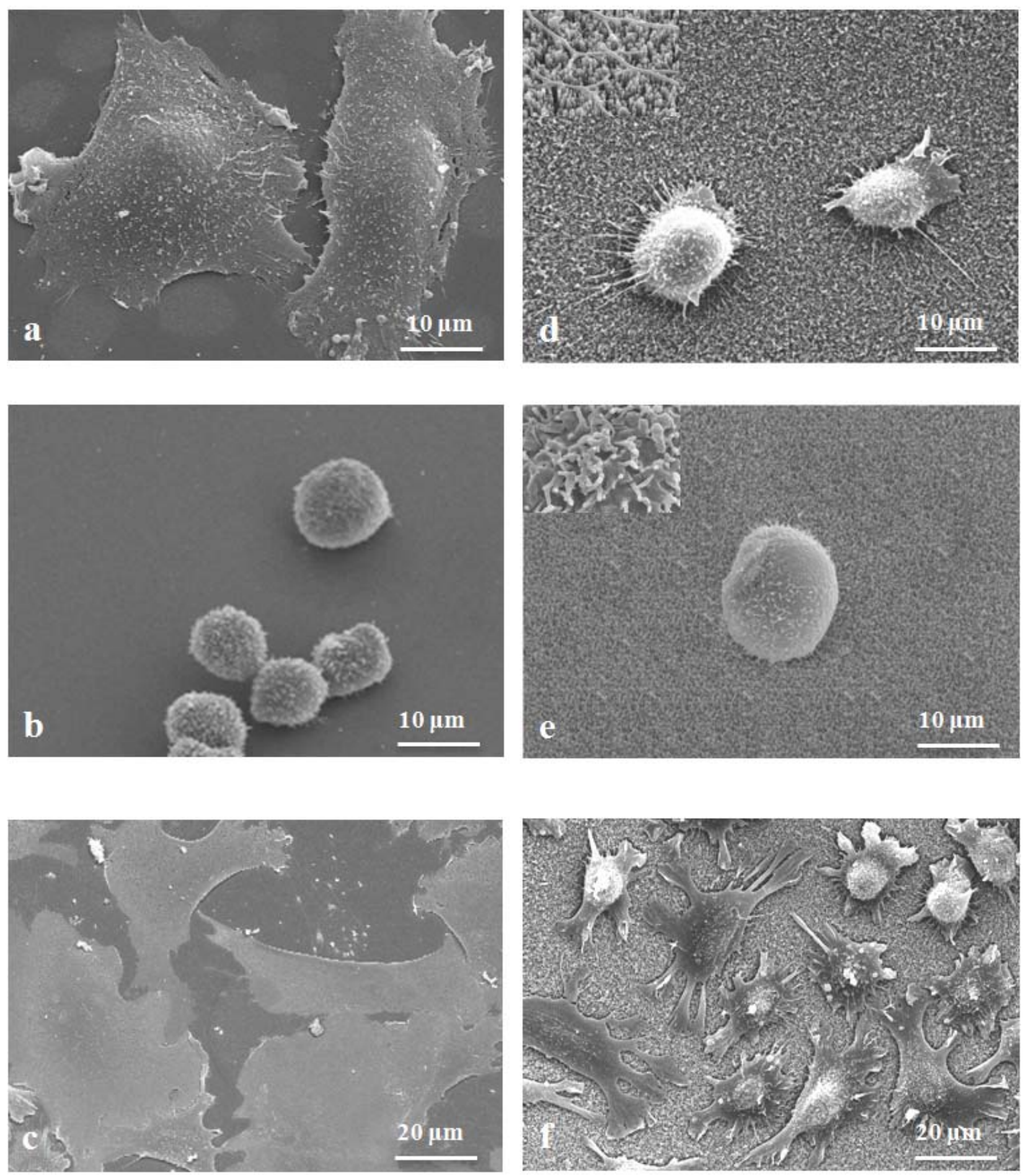

Fig. 3. SEM morphologies of CHO cells cultured on functionalized substrates after re-plating cells for $2 \mathrm{~h}$ on the below substrates: (A) Pristine oxidized silicon substrate; (B) FDTS-coated oxidized silicon substrate; (C) APTMScoated oxidized silicon substrate; (D) Pristine oxidized silicon nanosponge; (E) FDTS-coated oxidized silicon nanosponges; (F) APTMS-coated oxidized silicon nanosponges.

\section{Results}

\section{Surface characteristics of substrates}

The surface morphology and contact angle measurement were employed to determine the surface hydrophobicity of the aforementioned substrates, and the results showed that the contact angles were $29^{\circ} \pm 2^{\circ}, 110^{\circ} \pm 3^{\circ}, 41^{\circ} \pm 2^{\circ}$, $1^{\circ} \pm 1^{\circ}, 148^{\circ} \pm 4^{\circ}$ and $2^{\circ} \pm 1^{\circ}$ for pristine oxidized silicon substrates, FDTS-coated oxidized silicon substrates, APTMS-coated oxidized silicon substrates, pristine oxidized silicon nanosponges, FDTS-coated oxidized silicon nanosponges, and APTMS-coated oxidized silicon nanosponges, respectively (Fig. 2). Accordingly, FDTS has given rise to a contact angle of more than $90^{\circ}$, suggesting a hydrophobic property of the coated surfaces. In contrast, surfaces coated with APTMS remained hydrophilic and exhibited a contact angle of less than $90^{\circ}$. As expected, the resultant nano-topography of the surfaces could enhance the hydrophobicity emanating from the surfaced functional groups. In fact, both the pristine and APTMS- 

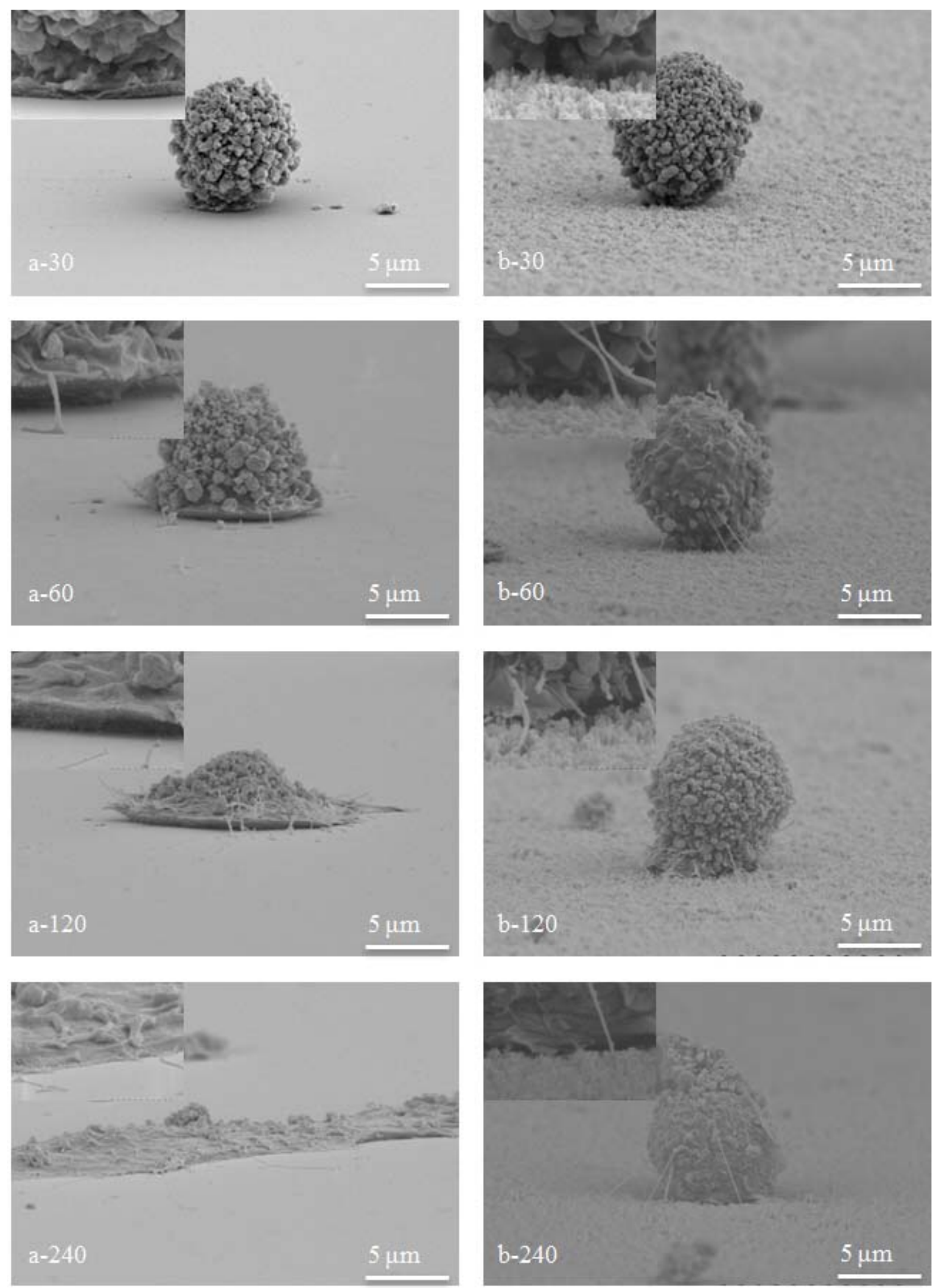

Fig. 4. SEM images of the contact phenomenon of cells cultured on pristine oxidized silicon substrate and pristine oxidized silicon nanosponges in response to different culturing times (a30-a240). Cells cultured on pristine oxidized silicon substrate for 30, 60, 120 and $240 \mathrm{~min}$, respectively. 
coated silicon nanosponges confer extremely low contact angles to water, consistent with the Gibbs surface energy theory (Cassie and Baxter, 1944; Wenzel, 1936; Yang et al., 2009). Additional surface characteristics were elucidated by atomic force microscopy and X-ray photoelectron spectrometer (for more details, please see supplementary data). The surface topographies of oxidized silicon substrates and nanosponges with surface modification were shown in supplementary Fig. 1. However, due to the shape of AFM tip and the size of nanosponges, surface topography of nanosponges is hard to regenerate. Therefore, surface topography of nanosponges measured by AFM showed some artifacts compared to SEM images (supplementary Fig. S1c and d). Nevertheless, as shown in supplementary Fig. S1, the surface topography did not exhibit significant changes after surface modification. Moreover, to confirm if the chemicals could be successfully coated on the substrates, we employed XPS to examine this (supplementary Fig. S2). In the case of FDTS-coated oxidized silicon substrate/ nanosponges, the XPS measurement showed strong peak at $696 \mathrm{eV}$, indicating the presence of the fluorine-containing molecules of FDTS on the substrate (supplementary Fig. 2a). As for the APTMS-coated oxidized silicon substrate, the N1s signal, shown in supplementary Fig. 2b, has two peaks centered at 399.6 and $401.3 \mathrm{eV}$, indicating the presence of the nitrogen-containing molecules of APTMS on the substrate. The peak at $399.6 \mathrm{eV}$ was assigned to the nitrogen in the free amino groups and that at the higher binding energy was taken to indicate hydrogen-bonded amine or positively charged quaternary nitrogen of the form $-\mathrm{NH}_{3}^{+}$.

\section{Morphology of CHO cells on different substrates}

To characterize how $\mathrm{CHO}$ cells interact with the aforementioned substrates, the cells were cultured on 1 $\mathrm{cm}^{2}$ oxidized silicon substrates and nanosponges with or without APTMS/FDTS on top (Fig. 1). After re-plating for $2 \mathrm{~h}$, the morphological appearances of the adhered $\mathrm{CHO}$ cells were imaged by SEM (Fig. 3). The CHO cells on the pristine oxidized silicon substrates appeared similar to those on the normal culture dishes (Fig. 3a). Intriguingly, on the pristine oxidized silicon nanosponges shown in Fig. $3 \mathrm{~d}$, the $\mathrm{CHO}$ cells stretched out and extended radial nanospikes from the cell edges, although they were prominently visualized as having a rounded-up shape. In contrast, in Fig. $3 \mathrm{~b}$ and $3 \mathrm{e}$, while $\mathrm{CHO}$ cells were cultured on the FDTS-coated substrates, nanospikes were no longer visualized despite the cells having a rounded-up shape and being relatively smaller in overall size. On the APTMScoated substrates, $\mathrm{CHO}$ cells were rather spread with no or shorter nanospikes on the pristine and nanosponge substrates respectively (Fig. 3c and 3f). The cells might spread up to $100 \mu \mathrm{m}$ in size on the APTMS-coated substrates (Fig. 3c), and this effect is attributed to the chemical properties of the $\mathrm{NH}_{2}^{+}$functional group of APTMS (Webb et al., 2000).

To illustrate the course of cell adhesion in a time dependent manner, $\mathrm{CHO}$ cells were imaged after a culturing duration of 30, 60, 120 and $240 \mathrm{~min}$. Fig. 4 shows the morphology of cells on the pristine oxidized silicon substrates and nanosponges at a magnification of $4.5 \mathrm{~K}$ (insets are at $65 \mathrm{~K}$ ). The enlarged contact area of the adhered cells, in association with the enhanced spreading, was found on the pristine oxidized silicon substrates at prolonged culturing periods. In accordance with the above observation, the contact sites of the cells on the pristine oxidized silicon substrates increased from several hundred $\mathrm{nm}$ after the first $2 \mathrm{~h}$, to several micrometers after another $2 \mathrm{~h}$ (Fig. 4a-30 to 4a-240). Although the pristine oxidized silicon substrates resulted in a marked flattened cell morphology, the cells on the pristine oxidized silicon nanosponges appeared to be rounded-up and were accompanied by a moderate increase in the contact area. Noticeably, there were numerous nanospikes emerging from the rounded-up cell bodies attached onto the surface nanorods of the oxidized silicon nanosponges, which may provide a physical support for cell adhesion onto the oxidized silicon nanosponges. Indeed, this phenomenon was exclusively observed in cells that had adhered onto the oxidized silicon nanosponges, since it is only visualized as a "glue-like" membrane extension on the pristine oxidized silicon substrates (insets in Fig. 4a-60 and 4b60).

\section{Cell cytoskeleton on different substrates}

The effects of nano-topography on cytoskeleton orientation and focal adhesion formation have been correlated to the shape and adhering nature of cells in response to specific extracellular environments (Chou et al., 1995). In light of the distinctive morphologies, as described above, we promptly examined the actin cytoskeleton organization of $\mathrm{CHO}$ cells, that had adhered to the aforementioned substrates, by means of immunofluorescent staining using Rhodamine-conjugated phalloidin. As shown in Fig. 5a, the distribution of actin filaments (stress fibers) were predominantly across the center of the cell bodies cultured on the pristine oxidized silicon substrates, similar to that observed on ECM-coated glass coverslips (data not shown). However, the $\mathrm{CHO}$ cells cultured on the pristine oxidized silicon nanosponges displayed F-actin that was primarily clustered in a punctuate manner, which might represent the contact sites of the cell-extracellular nanotopography, as indicated by the arrows in Fig. 5d. Cortical actin bundles predominantly appeared at the peripheries of the cells, consistent with a less-spreading and roundedup morphology. These results suggest that a potential restriction of actin polymerization in one direction occurs when cells encounter nanoscale contact sites on the oxidized silicon nanosponges, rather than an actin fiber network connected by a $70^{\circ}$ angle at the leading edge of the adhered cell membrane on the pristine oxidized silicon substrates (Blanchoin et al., 2000; Mullins et al., 1998). It should be noted that the restriction of actin polymerization in one direction, opposite to the nanoscale contact sites, was not influenced by the surface chemistry, since it remained markedly displayed in the cells that had adhered to the oxidized silicon nanosponges coated with either FDTS or APTMS (Figs. 5e and 5f) compared with the oxidized silicon substrates (Figs. 5a-c). Taken together, 

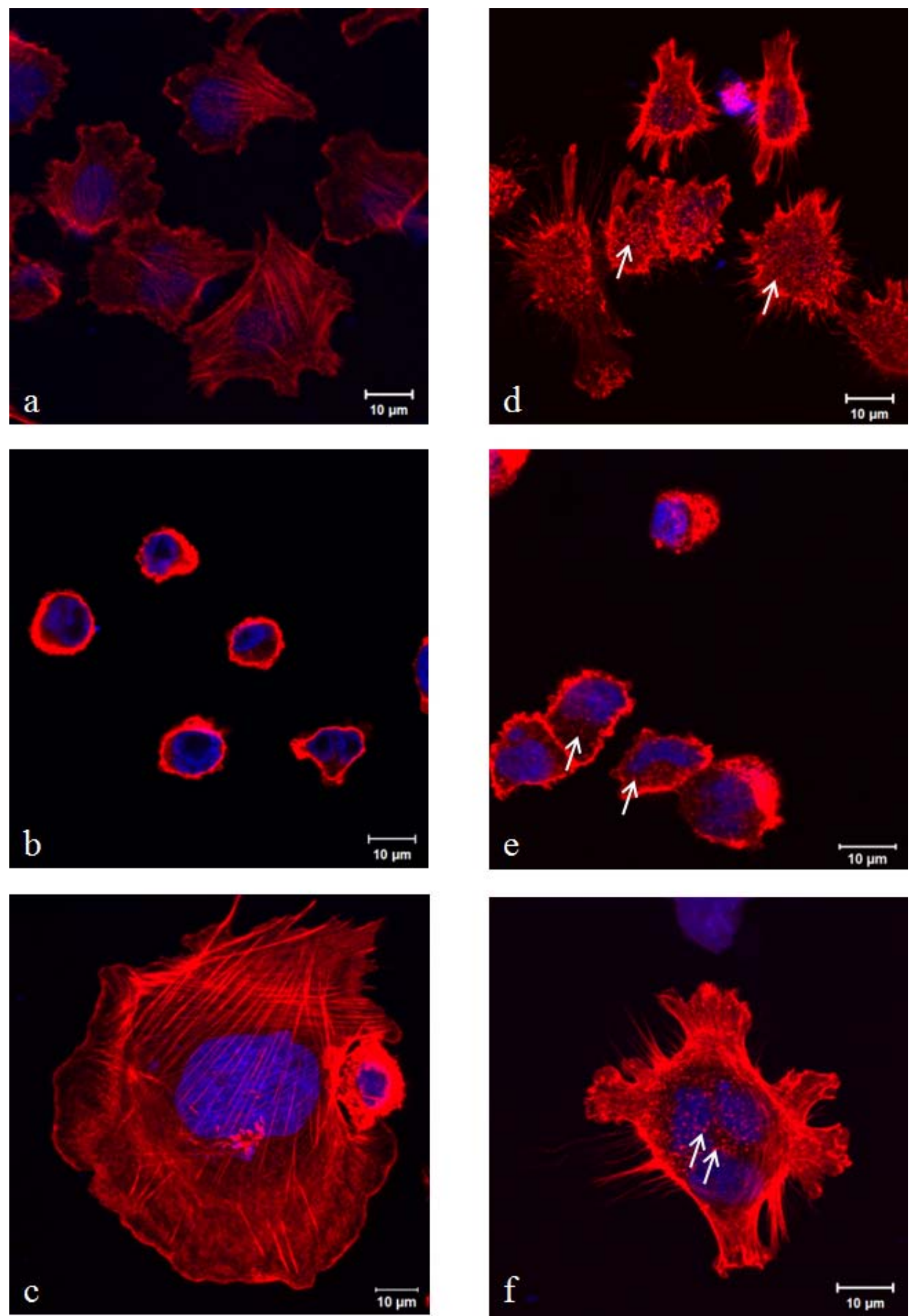

Fig. 5. Laser scanning confocal microscope images of the cytoskeleton and nuclei of cells cultured on functionalized substrates: (A) Pristine oxidized silicon substrate; (B) FDTS-coated oxidized silicon substrate; (C) APTMS-coated oxidized silicon substrate; (D) Pristine oxidized silicon nanosponge; (E) FDTS-coated oxidized silicon nanosponges; (F) APTMS-coated oxidized silicon nanosponges. The arrows in D-F indicate F-actin clustering into small punches. 

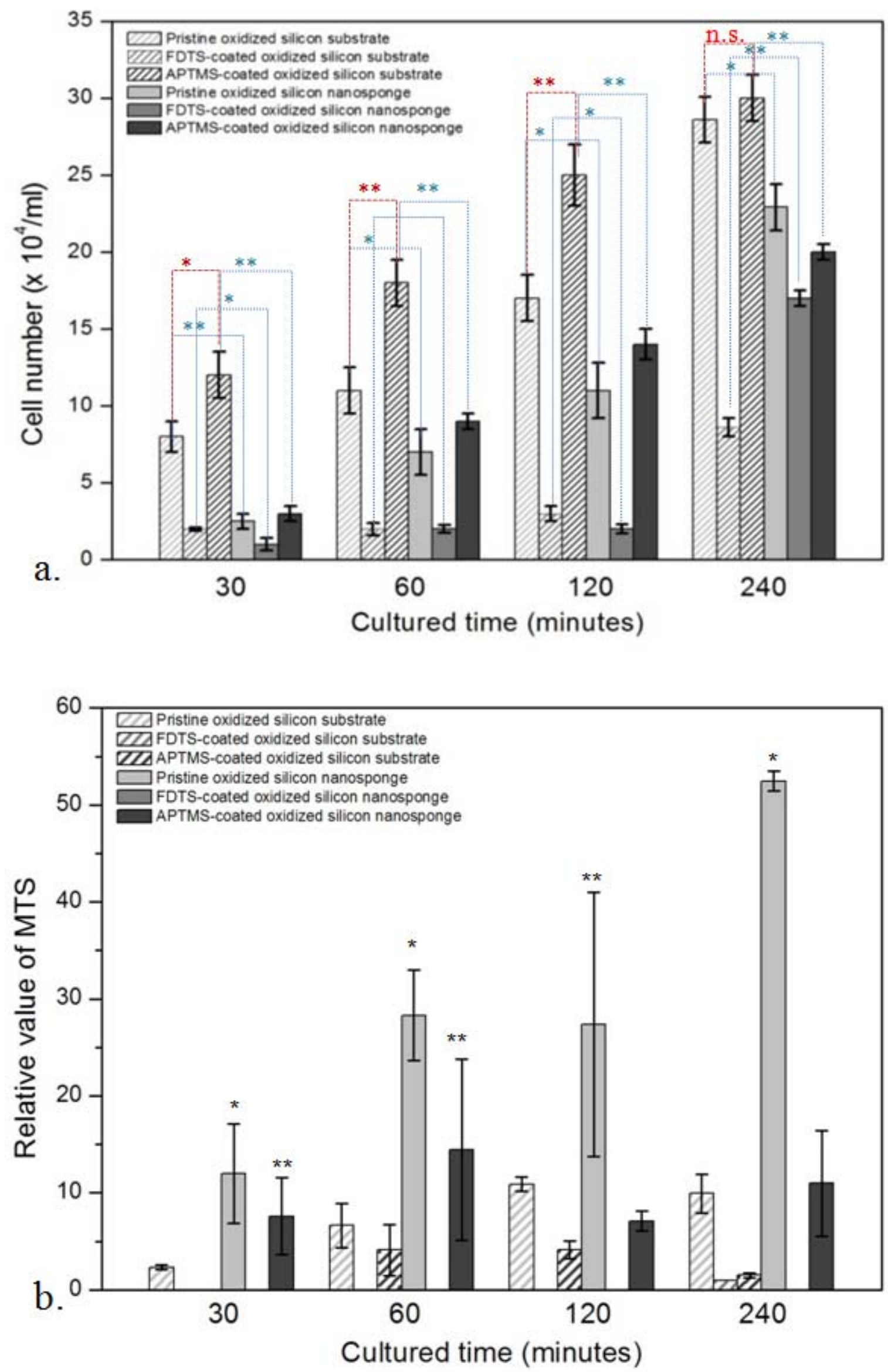

Fig. 6. The relationship between the cell attachment (A), or average viability of the attached cells, (B) at the short period of culture time $(30,60,120$ and $240 \mathrm{~min})$ on various functionalized substrates. The mean $+\mathrm{SD}$ from at least three experiment is shown. ${ }^{*} P<0.01 ; * * P<0.05$. The $P$ values were compared with the pristine oxidized silicon substrates unless indicated. 


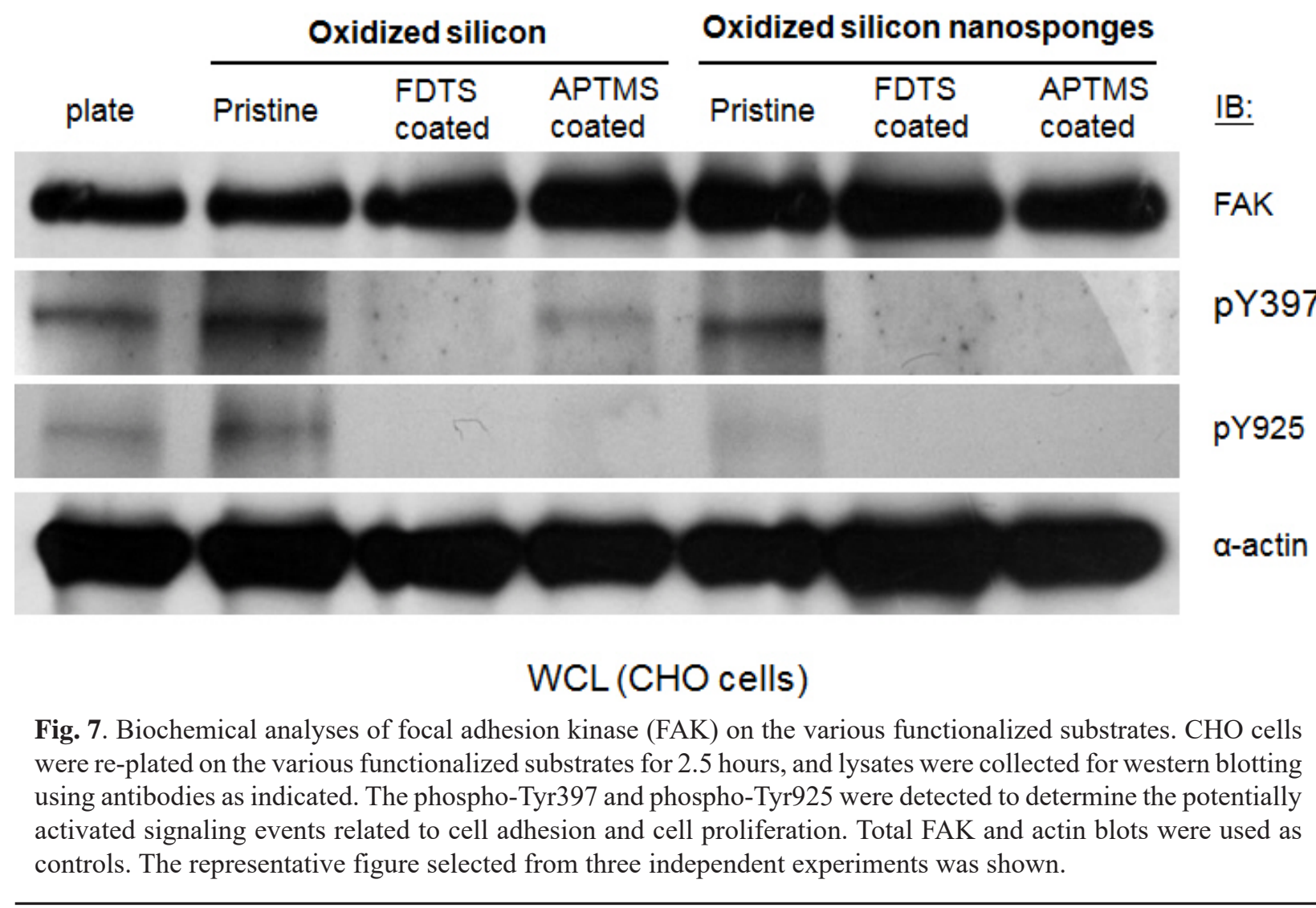

the observations of cell interaction with the nanoscale contact sites on the oxidized silicon nanosponges provide novel insights into biomimicing in vivo cell-ECM interactions, which differ greatly from the general cellsplanar surface interactions currently used in cell culture conditions in vitro.

\section{Cell adhesion and viability on different substrates over time}

To explore the time-dependent characteristic of the aforementioned substrates on cell adhesion, cell adhesion assays were performed by re-plating $\mathrm{CHO}$ cells at various time intervals (i.e., 30, 60, 120 and $240 \mathrm{~min}$ ). Cell adhesion was measured by counting the retained cells on the substrates after the PBS wash as described in Materials and Methods. Statistical calculation derived from five repeated experiments shown in Fig. 6a demonstrated that cell adhesion rapidly increases in association with a prolonged re-plating period up to $240 \mathrm{~min}$. The enhancement of cell adhesion was obviously observed in a prominent increase on the nanosponges than on the pristine oxidized silicon substrates (i.e., planar). Neither of the two-type chemical coated substrates led to the promotion of cell adhesion when compared to their pristine counterparts, on which cells rather remain unaffected or suppressed. Interestingly, of all of the tested substrates, cell adhesion was hardly seen on the FDTS-coated pristine oxidized silicon substrates or nanosponges. These results implicate that the physical property of the nano-topography is a predominated factor in the stimulation of cell adhesion, whereas the effects by chemical are dependent on specific chemical properties. Consistently, the nanosponges rather than the surface chemical nature recapitulate a similar consequence of cell attachment in cell viability of average adhered CHO cells on them by MTS measurement (Fig. $6 \mathrm{~b}$ ), suggesting a predominant effect of the nanotopography in cellular and physiological functions. Likewise, we found that the distinctive surface chemical property of substrate enables resulting in the discrepancies of cell viability.

\section{Biochemical insights}

Focal adhesion kinase (FAK) is a $125 \mathrm{KDa}$ cytoplasmic tyrosine kinase that plays a key role in integrin-mediated signal transduction pathways in response to cell adhesion, migration, proliferation, and so on (Cary and Guan, 1999; Schlaepfer et al., 1999). Upon integrin engagement with ECM molecules, FAK is translocated to focal contacts and autophosphorylates at its own Tyr-397 (Cary and Guan, 1999; Schlaepfer et al., 1999). The activation of FAK is followed by its association with a number of SH2 ( $\mathrm{Src}$ homology 2) domain containing signaling proteins, including Src family kinases (Cobb et al., 1994; Schaller et al., 1994), the p85 regulatory subunit of PI3K (Chen and Guan, 1994), phospholipase C- $\gamma$ (Zhang et al., 1999), and Grb7 (Han and Guan, 1999). The formation of the FAK/Src complex has been demonstrated to allow the phosphorylation of Y925 of FAK by Src, which binds to the $\mathrm{SH} 2$ domain of Grb2 and relays FAK signaling to the MAP kinase cascade, by which FAK enables promoting cell cycle progression (Schaller et al., 1994).

To further explore the effect of the interaction between $\mathrm{CHO}$ cells and the aforementioned substrates, we conducted biochemical analyses. As a represent result shown in Fig. 7, focal adhesion kinase (FAK), a key signaling protein tyrosine kinase downstream of the cell- 

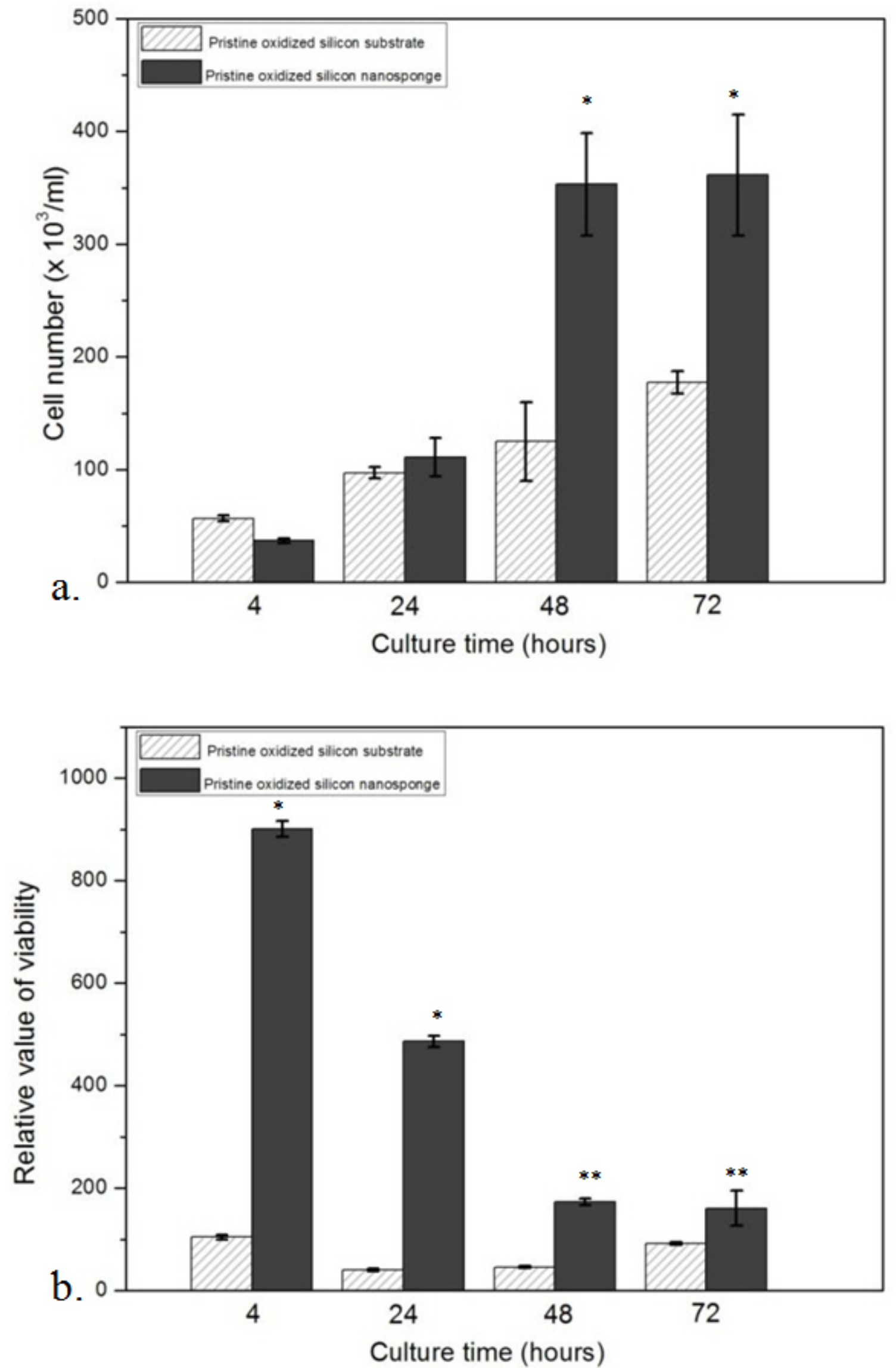

Fig. 8. The relationship between the cell attachment (A), or average viability of the attached cells, (B) at the long period of cultured time $(4,24,48$ and $72 \mathrm{~h})$ on the pristine oxidized silicon substrates and the nanosponges. The mean $+\mathrm{SD}$ from at least three experiments is shown. ${ }^{*} P<0.01 ; * * P<0.05$. All of the $P$ values were compared between the pristine oxidized silicon substrates and the nanosponges at the same time points. 
ECM adhesion receptor family called integrins, was examination for its phosphorylation status at Tyr-397 and Tyr-925, which are known important phosphorylated sites on FAK in mediating cell migration and/or proliferation, respectively. We found that the phospho-Tyr-397 of FAK was significantly elevated on the pristine oxidized silicon substrates and the pristine oxidized silicon nanosponges, but moderately on the APTMS-coated oxidized silicon substrates. Unexpectedly, the phoshpo-Tyr-397 was not observed on the APTMS-coated oxidized silicon nanosponges. As mentioned previously, the increase of phospho-Tyr-397 of FAK is associated with activation of integrins in response to cell adhesion with ECM molecules (Cary and Guan, 1999; Schlaepfer et al., 1999). However, its levels were moderate or absent on both APTMS-coated substrates, even though, as revealed in Fig. 3, the cells were extensively spread on these APTMS-coated substrates. Therefore, we hypothesized that cell adhesion mediated by APTMS might occur independently of integrins. However, the elevated phospho-Tyr-925 was only seen on the pristine oxidized silicon substrates but not on other substrates. This finding suggests that silicon nanosponges might be unable to promote cell proliferation but retain an efficient survival rate for cells. Indeed, we found that attached cell number is similar between the pristine oxidized silicon substrates and nanosponges over a long period culture (i.e., 4, 24, 48 and 72 h; Fig. 10a) whereas cells on silicon nanosponges exhibited higher viability of each attached cell than on the pristine oxidized silicon substrates in a long term culture condition (Fig. $8 b)$. Together, these results implicate that, in addition to remaining an attachable substrate, the nanotopography supports a better cell viability than planner structure substrates.

\section{Discussion}

Microenvironmental cues direct a number of cell functions, such as adhesion, growth, survival, proliferation, migration, differentiation, and cell death. Through physical interactions between cells and these surrounding cues/ surfaces, some changes in morphology, biochemistry, and physiology occur so that the cells can adapt to an appropriate situation and behavior in the presence of specific extracellular conditions. In the present study, we generated a biomimetic $3 \mathrm{D}$ oxidized silicon nanosponge substrate and demonstrated that cells can adhere to and can be maintained on this substrate. By analyzing the cell morphological appearance, biochemical changes, and by performing functional characterizations of the oxidized silicon substrates and the oxidized silicon nanosponges in combination with FDTS or APTMS chemical modification, we depicted the merit of the oxidized silicon nanosponges for understanding the responses of cells in contact with nanoscaled surfaces and for biomimicing the in vivo nanoscale environment for bioengineering applications.

Filopodia are slender, fingerlike membrane projections that function as antennae for cells to probe their environment. Therefore, the filopodia stretch out from the edge of the cells, attaching onto extracellular surfaces through the formation of adherent structures. These filopodia-like structures are markedly visualized when cells were cultured on the pristine oxidized silicon nanosponges, as shown in figure $3 \mathrm{~d}$. However, they were no longer seen on FDTS-coated substrates. Indeed, numerous studies have investigated how surface wettability and charge may influence cell adhesion, shape, and spreading (Van der Valk et al., 1983; Webb et al., 1998; Webb et al., 2000; Arima and Iwata, 2007), suggesting that enhanced cell spreading occurs on hydrophilic surfaces rather than on hydrophobic surfaces. Our data showed that cell morphology varied with the surface hydrophobicity (correlated to wettability); however, no direct relationship between cell spread and the topography of the substrates was apparent (Fig. 5). In other words, when the surface was coated with functional groups, the cell shape on different topographies was quite similar. However, in the absence of functional groups present on the substrates, the surface topography influenced the cell behavior (Fig. 5a and 5d). These data indicate a dominant role of the chemical properties of contact surfaces in directing cellular behaviors, or at least cell adhesion.

Previous reports have demonstrated that when cells adhere onto anisotropic structures, most of the cells are elongated and preferentially follow along the structures. This phenomenon is called "contact guidance", and it occurs in different cell types, such as macrophages, epithelia, fibroblasts, and neuronal cells (Flemming et al., 1999; Bromberek et al., 2002; Teixeira et al., 2003). The chemical nature of the substrate is also important for eliciting contact guidance, because cells cultured on substrates with different chemical compositions confer an impetus to the topography-mediated contact guidance (Bromberek et al., 2002). In contrast, in certain studies, contact guidance was shown to be independent of the surface chemistry but is affected only by the architectures of the substrates (Den Braber et al., 1995). As a result, these studies indicate that contact guidance intimately depends on the length scale of the topographical features of the cell culture substrates (Dunn and Health, 1976; Clark et al., 1987). In the present study, cell spreading onto the APTMS-coated oxidized silicon nanosponges was found to be enhanced in comparison with the pristine ones. Noticeably, the overall cell adhesion onto the APTMScoated oxidized silicon nanosponges was independent of integrins due to fact that the phospho-Tyr-397 was not increased. In addition, we observed that less actin stress fibers were formed in the cells adhered onto the APTMScoated oxidized silicon nanosponges. Instead, a number of contact punches between the cell membrane and the nanoscale surfaces of the oxidized silicon nanosponges were predominantly observed, suggesting that the physical topographical features of the oxidized nanosponges are relatively important attribution for this "contact guidance". The physical characteristics of the surface used for the oxidized silicon nanosponges that affect the contact guidance are currently under investigation. Nevertheless, the nanoscale surface of the oxidized silicon nanosponges may provide an in vivo biomimicing surface for understanding the interactions between cells and ECMs.

One of major challenges in developing tissue engineered devices is how to culture cells on synthetic 
Table 1. An overview of the effects of CHO cells cultured on the various functionalized substrates.

\begin{tabular}{|c|c|c|c|c|c|c|c|c|}
\hline & & \multirow{2}{*}{$\begin{array}{l}\text { Glass } \\
\text { Plate }\end{array}$} & \multicolumn{3}{|c|}{ Oxidized Silicon } & \multicolumn{3}{|c|}{ Oxidized Silicon Nanosponge } \\
\hline & & & pristine & $\begin{array}{l}\text { FDTS } \\
\text { coated }\end{array}$ & $\begin{array}{l}\text { APTMS } \\
\text { coated }\end{array}$ & pristine & $\begin{array}{l}\text { FDTS } \\
\text { coated }\end{array}$ & $\begin{array}{l}\text { APTMS } \\
\text { coated }\end{array}$ \\
\hline \multicolumn{2}{|c|}{ Functional Group } & $\mathrm{OH}^{-}$ & $\mathrm{OH}^{-}$ & $\mathrm{F}^{-}$ & $\mathrm{NH}_{2}^{+}$ & $\mathrm{OH}^{-}$ & $\mathrm{F}^{-}$ & $\mathrm{NH}_{2}^{+}$ \\
\hline \multicolumn{2}{|c|}{$\begin{array}{l}\text { Hydrophobicity } \\
\text { (contact angle) }\end{array}$} & $30 \pm 2^{\circ}$ & $29 \pm 2^{\circ}$ & $110 \pm 3^{\circ}$ & $41 \pm 2^{\circ}$ & $1 \pm 1^{\circ}$ & $148 \pm 4^{\circ}$ & $2 \pm 1^{\circ}$ \\
\hline \multicolumn{2}{|c|}{$\begin{array}{c}\text { Cell Adhesion } \\
\text { (after } 2 \text { hrs) } \\
\left(* 10^{4} \text { cells } / \mathrm{ml}\right)\end{array}$} & 20 & 40 & 2 & 28 & 78 & 2 & 61 \\
\hline \multicolumn{2}{|c|}{ Cell morphology } & flattened & flattened & rounded & flattened & $\begin{array}{l}\text { rounded }+ \\
\text { slightly } \\
\text { flattened }\end{array}$ & rounded & $\begin{array}{r}\text { rounded + } \\
\text { flattened }\end{array}$ \\
\hline \multirow{4}{*}{ Cytoskeleton } & $\begin{array}{c}\text { Central stress } \\
\text { fiber }\end{array}$ & ++ & ++ & - & +++ & + & - & + \\
\hline & $\begin{array}{c}\text { Cortical actin } \\
\text { fiber }\end{array}$ & - & - & +++ & - & ++ & +++ & + \\
\hline & Protrusions & - & + & - & - & +++ & - & ++ \\
\hline & Punches & - & - & - & - & +++ & + & ++++ \\
\hline \multicolumn{2}{|c|}{ Cell viability (120 minutes) } & ++ & ++ & NA & + & ++++ & NA & ++ \\
\hline \multicolumn{2}{|c|}{ Cell viability (72 hours) } & NA & ++ & NA & NA & +++ & NA & NA \\
\hline \multicolumn{2}{|c|}{$\begin{array}{c}\text { pY397 FAK } \\
\text { (Cell-ECM attachment) }\end{array}$} & ++ & ++ & - & + & ++ & - & - \\
\hline \multicolumn{2}{|c|}{$\begin{array}{c}\text { pY925 FAK } \\
\text { (cell cycle progression) }\end{array}$} & + & ++ & - & - & + & - & - \\
\hline
\end{tabular}

materials in vitro by directing their differentiated properties and functions. Previous studies have proposed that the intrinsic effects of cell spreading, shape, and cytoskeleton organization on cell differentiation might be closely correlated to the cell's external surroundings (Singhvi et al., 1994; Evans et al., 2009). For example, muscle cells are slender and usually show specific direction in vivo but exhibit no specific direction in in vitro culture conditions. Therefore, our oxidized silicon nanosponges can probably be used to replace the complicated setting employed for bioengineering scaffolding in the future. In addition, our preliminary result also showed that the nanosponges could lead to a better viability in human corneal epithelial cells (HCECs), a primary human cell line derived from human corneal epithelial cells, in comparison with pristine oxidized silicon substrates (unpublished data).

In summary, the differential responses of $\mathrm{CHO}$ cells on the various oxidized silicon substrates are compared in Table 1 and can be described as follows. First, cell adhesion is mainly determined by the surface hydrophobicity, although the cells may tend to adhere to hydrophilic surfaces rather than to hydrophobic ones. Surface hydrophobicity primarily depends on the functional groups of the surfaces, while the surface nano-topography pushes the surface hydrophobicity to the extreme. Second, a distinct morphology, flattened versus rounded, has been observed on either the oxidized silicon substrates or on the oxidized silicon nanosponges, corresponding to the presence of central stress fibers on the hydrophilic surfaces (i.e., pristine and APTMS-coated oxidized silicon substrates) rather than on the hydrophobic ones with much cortical stress fibers (i.e., FDTS-coated substrates), where a large number of cortical stress fibers was apparent. Interestingly, on the pristine oxidized silicon nanosponge, the cells retained, to some extent, a rounded shape with significant cortical stress fibers and detectable central stress fibers, suggesting an extended regulation of cell morphology by a combination of physical and chemical characteristics. Additionally, the oxidized silicon nanosponges give rise to some marked cytoskeletal organizations displayed as nano-actin punches and slender actin fiber protrusions from upper cell surfaces, the dimensions of which are similar to the nanorods of the oxidized nanosponges, onto the nano-contact sites between the cells and the extracellular surfaces (i.e., various types of ECMs). Third, both the oxidized silicon substrates and nanosponges can provide an environment for cell survival. In agreement with the activation of FAK, its phosphoTyr397 is elevated while CHO cells are cultured on both the oxidized silicon substrates and nanosponges. However, the phospho-Tyr925 of FAK is not obviously augmented on the nanosponges.

\section{Conclusions}

Our newly developed nano-topographic oxidized silicon nanosponges provide more flexibility in manipulating cell morphogenesis and understanding the biochemical, physiological, and functional responses of a cell in a biomimicing environment in vitro. In particular, we unravel the close relationships for cell adhesion and hydrophobicity as well as the cell morphological regulation and nanotopography of contact surfaces. Accordingly, the utilization 
of nano-topographic oxidized silicon nanosponges in bioengineering is expected to be beneficial to complex tissue manipulations.

\section{Acknowledgements}

We thank Instrument Technology Research Center (ITRC) for CPD treatment, SEM imaging and immunofluorescent supports. We also gratefully thank Chia-Yao Lee for technical assistance. The study is supported by the grant from National Science Council (NSC- 98-2218-E-007$004)$ to J. A. Yeh and the grants from National Science Council (NSC-96-2311-B-002-023-MY3) and National Health Research Institute (NHRI-EX98-9723SC) to T.L.Shen.

\section{Supplementary Data}

\section{Supplementary Materials and Methods}

\section{AFM measurements}

The AFM apparatus employed in the experiments is a Bioscope AFM (Digital Instruments, Veeco, Plainview, NY, USA). Topographic images of surfaces were regenerated with data measured in the tapping mode (TM). The material characteristics of the sample indicated the inherent elasticity in terms of hardness, magnetic and electric forces. Relative to a contact mode or a non-contact mode, the tapping mode experiences smaller forces and incurs less damage to the sample. TM-AFM typically shows greater lateral resolution than a non-contact-mode AFM because the resolution in the non-contact mode is limited by the separation between the tip and the sample due to a van der Waals attractive force. In addition, we employed rectangular shaped $\mathrm{NCH}$ cantilevers (Nanoworld AG, Neuchâtel, Switzerland) rated for a nominal spring coefficient $42 \mathrm{~N} / \mathrm{m}$ and resonance frequency $320 \mathrm{kHz}$. The cantilevers were cleaned with ethanol and immediately rinsed with de-ionized water before use. As the tip traced various surface textures, its displacement was monitored and rendered into topographic images with a computer. Topographic images were captured and regenerated by the software (Nanoscope (R) III v5.31R1).

\section{XPS measurement}

In order to analyze the conditions of chemical-coated surfaces, high resolution X-ray photoelectron spectrometer (HRXPS) was used to examine the surface. HRXPS (ULVAX-PHI, PHI Quantera SXM, Japan) was equipped with the light source of scanning monochromated $\mathrm{Al}$ anode and energy analyzer of $180^{\circ}$ spherical capacitor analyzer with 32 channel detector. XPS analysis was performed at room temperature, with $1486.6 \mathrm{eV}$ X-ray from the $\mathrm{Al} \mathrm{K} \mathrm{K}_{\alpha}$ line and a $45^{\circ}$ incident angle measured from the sample surface. Samples were loaded into an ultrahigh vacuum chamber, approximately $5 \times 10^{-10}$ Torr, of an M-probe surface spectrometer.

\section{Results}

Supplementary results are shown in Figs. S1 and S2.
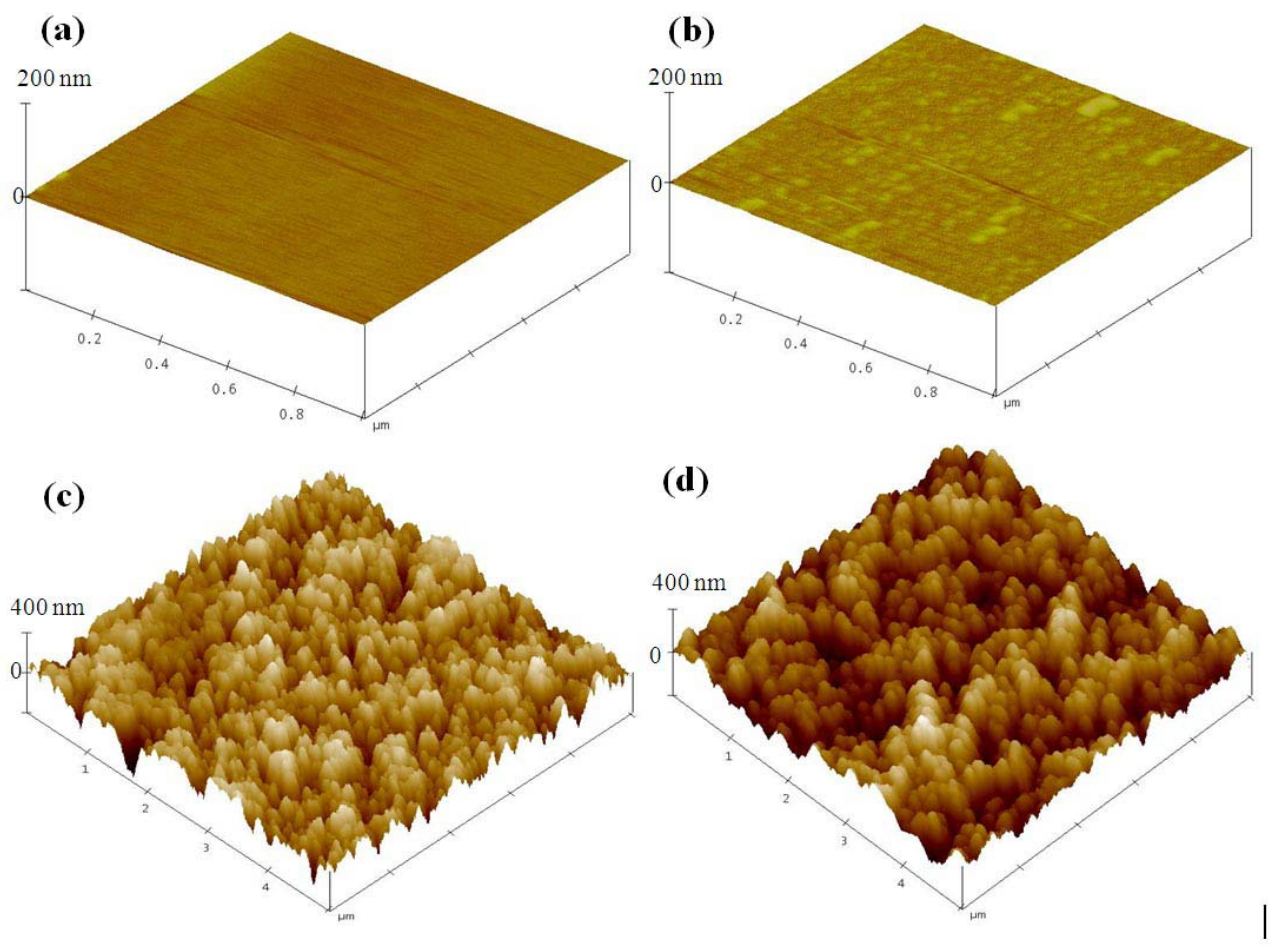

Fig. S1. Surface topography of (a) FDTS-coated; (b) APTMS-coated oxidized silicon substrate; (c) FDTScoated; (d) APTMS-coated oxidized silicon nanosponges. 


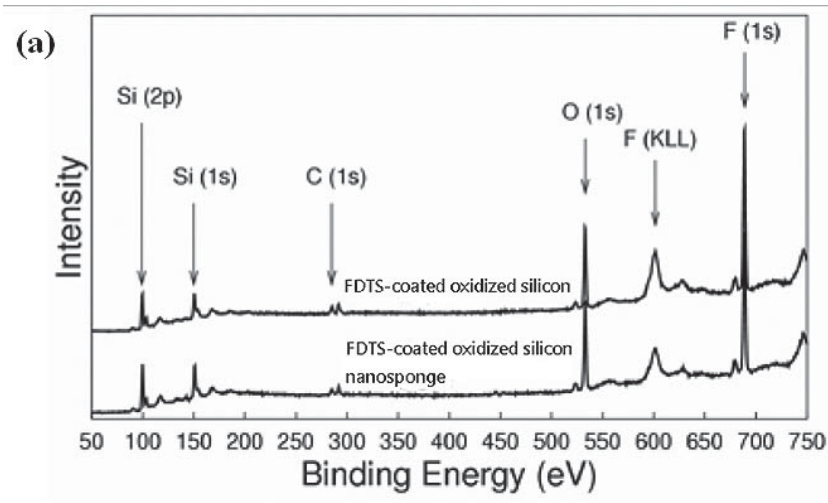

Fig. S2. XPS spectra of (a) FDTS-coated substrates; (b) APTMS-coated substrate.

(b)

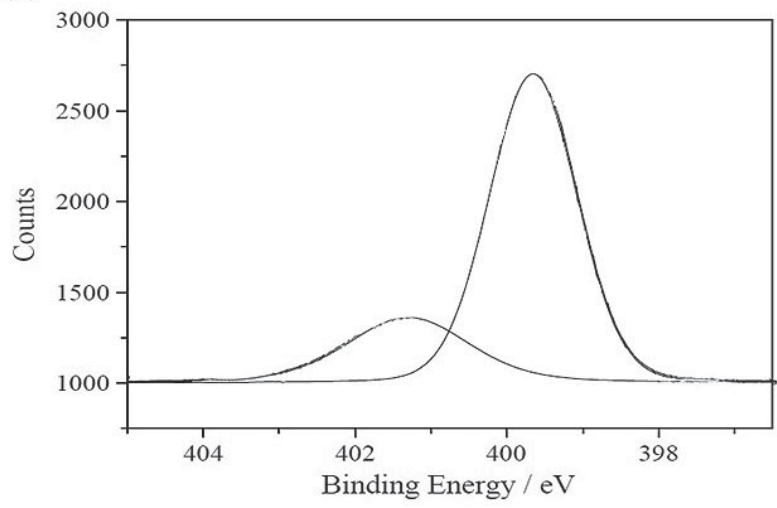

\section{References}

Andersson AS, Backhed F, von Euler A, RichterDahlfors A, Sutherland D, Kasemo B (2003) Nanoscale features influence epithelial cell morphology and cytokine production. Biomaterials 24: 3427-3436.

Arima Y, Iwata H (2007) Effect of wettability and surface functional groups on protein adsorption and cell adhesion using well-defined mixed self-assembled monolayers. Biomaterials 28: 3074-3082.

Blanchoin L, Amann KJ, Higgs HN, Marchand JB, Kaiser DA, Pollard TD (2000) Direct observation of dendritic actin filament networks nucleated by Arp2/3 complex and WASP/Scar proteins. Nature 404: 1007-1011.

Bromberek BA, Enever PAJ, Shreiber DI, Caldwell MD, Tranquillo RT (2002) Macrophages influence a competition of contact guidance and chemotaxis for fibroblast alignment in a fibrin gel coculture assay. Exp Cell Res 275: 230-242.

Cary LA, Guan JL (1999) Focal adhesion kinase in integrin-mediated signaling. Front Biosci 4: D102-113.

Cassie ABD, Baxter S (1944) Wettability of porous surfaces. Trans Faraday Soc 40: 546-550.

Chen HC, Guan JL (1994) Association of focal adhesion kinase with its potential substrate phosphatidylinositol 3-kinase. Proc Natl Acad Sci USA 91: 10148-10152.

Choi CH, Hagvall SH, Wu BM, Dunn JCY, Beygui RE, Kim CJ (2007) Cell interaction with three-dimensional sharp-tip nanotopography. Biomaterials 28: 1672-1679.

Chou L, Firth JD, Uitto VJ, Brunette DM (1995) Substratum surface topography alters cell shape and regulates fibronectin mRNA level, mRNA stability, secretion and assembly in human fibroblasts. J Cell Sci 108: 1563-1573.

Chyan JY, Hsu WC, Yeh JA (2009) Broadband antireflective poly-Si nanosponge for thin film solar cells. Opt Express 17: 4646-4651.

Clark P, Connolly P, Curtis ASG, Dow JAT, Wilkinson CDW (1987) Topographical control of cell behaviour. I. Simple step cues. Development 99: 439-448.

Cobb BS, Schaller MD, Leu TH, Parsons JT (1994) Stable association of pp60src and pp59fyn with the focal adhesion-associated protein tyrosine kinase, pp125FAK. Mol Cell Biol 14: 147-155.

Dalby MJ, Childs S, Yarwood SJ, Riehle MO, Johnstone HJH, Affrossman S, Curtis ASG (2003) Fibroblast reaction to island topography: changes in cytoskeleton and morphology with time. Biomaterials 24: 927-935.

Dalby MJ, Riehle MO, Sutherland DS, Agheli H, Curtis ASG (2005) Morphological and microarray analysis of human fibroblasts cultured on nanocolumns produced by colloidal lithography. Eur Cells Mater 9: 1-8.

Den Braber ET, De Ruijter JE, Smits HTJ, Ginsel LA, Von Recum AF, Jansen JA (1995) Effect of parallel surface microgrooves and surface energy on cell growth. J Biomed Mater Res 29: 511-518.

Dunn GA, Health JP (1976) A new hypothesis of contact guidance in tissue cells. Exp Cell Res 101: 1-14.

Evans ND, Minelli C, Gentleman E, Lapointe V, Patankar SN, Kallivretaki M, Chen X, Roberts CJ, Stevens MM (2009) Substrate stiffness affects early differentiation events in embryonic stem cells. Eur Cells Mater 18: 1-14.

Even-ram S, Yamada KM (2005) Cell migration in 3D matrix. Curr Opin Cell Biol 17: 524-532. 
Flemming RG, Murphy CJ, Abrams GA, Goodman SL, Nealey PF (1999) Effects of synthetic micro- and nanostructured surfaces on cell behavior. Biomaterials 20: 573588.

Friedl P, Zänker KS, Brücker EB (1998) Cell migration strategies in 3-D extracellular matrix: Differences in morphology, cell matrix interactions, and integrin function. Microsc Res Tech 43: 369-378.

Graeter SV, Huang J, Perschmann N, López-García M, Kessler H, Ding J, Spartz JP (2007) Mimicking cellular environments by nanostructured soft interfaces. Nano Lett 7: 1413-1418.

Han DC, Guan JL (1999) Association of focal adhesion kinase with Grb7 and its role in cell migration. J Biol Chem 274: 24425-24430.

Jungbauer S, Kemkemer R, Gruler H, Kaufmann D, Spatz JP (2004) Cell shape normalization, dendrite orientation, and melanin production of normal and genetically altered (Haploinsufficient NF1)-Melanocytes by microstructured substrate interactions. ChemPhysChem 5: 85-92.

Keselowsky BG, Collard DM, García AJ (2004) Surface chemistry modulates focal adhesion composition and signaling through changes in integrin binding. Biomaterials 25: 5947-5954.

Kobrin B, Chinn J, Ashurst WR, Maboudian R (2005) Molecular vapor deposition (MVD) for improved SAM coatings. Proc SPIE 5716: 151-157.

Langer R, Vacanti JP (1993) Tissue engineering. Science 260: 920-926.

Lee KB, Park SJ, Mirkin CA, Smith JC, Mrksich M (2002) Protein nanoarrays generated by dip-pen nanolithography. Science 295: 1702-1705.

Low SP, Voelcker NH, Canham LT, Williams KA (2009) The biocompatibility of porous silicon in tissues of the eye. Biomaterials 30: 2873-2880.

Marks Jr SC (2005) A discrepancy between measurements of bone resorption in vivo and in vitro in newborn osteopetrotic rats. Am J Anat 141: 329-340.

Mullins RD, Heuser JA, Pollard TD (1998) The interaction of Arp2/3 complex with actin: Nucleation, high affinity pointed end capping, and formation of branching networks of filaments. Proc Natl Acad Sci USA 95: 61816186.

Neff JA, Caldwell KD, Tresco PA (1998) A novel method for surface modification to promote cell attachment to hydrophobic substrates. J Biomed Mater Res 40: 511 519.

Peng K, Hu J, Yan Y, Wu Y, Fang H, Xu Y, Lee ST, Zhu J (2006) Fabrication of single-crystalline silicon nanowires by scratching a silicon surface with catalytic metal particles. Adv Funct Mater 16: 387-394.

Pesen D, Haviland DB (2009) Modulation of cell adhesion complexes by surface protein patterns. Appl Mater Interfaces 1: 543-548.
Qi S, Yi C, Ji S, Fong CC, Yang M (2009) Cell adhesion and spreading behavior on vertically aligned silicon nanowire arrays. Appl Mater Interfaces 1: 30-34.

Romanova EV, Oxley SP, Rubakhin SS, Bohn PW, Sweedler JV (2006) Self-assembled monolayers of alkanethiols on gold modulate electrophysiological parameters and cellular morphology of cultured neurons. Biomaterials 27: 1665-1669.

Sapelkin AV, Bayliss SC, Unal B, Charalambou A (2006) Interaction of B50 rat hippocampal cells with stainetched porous silicon. Biomaterials 27: 842-846.

Schlaepfer DD, Hauck CR, Sieg DJ (1999) Signaling from focal adhesion kinase. Prog Biophys Mol Biol 71: 435-478.

Schaller MD, Hildebrand JD, Shannon JD, Fox JW, Vines RR, Parsons JT (1994) Autophosphorylation of the focal adhesion kinase, pp125FAK, directs SH2-dependent binding of pp60src. Mol Cell Biol 14: 1680-1688.

Shen TL, Park AY, Alcaraz A, Peng X, Jang I, Koni P, Flavell RA, Gu H, Guan JL (2005) Conditional knockout of focal adhesion kinase in endothelial cells reveals its role in angiogenesis and vascular development in late embryogenesis. J Cell Biol 169: 941-952.

Singhvi R, Kumar A, Lopez G, Stephanopoulos GN, Wang DIC, Whitesides GM (1994) Engineering cell shape and function. Science 264: 696-698.

Teixeira AI, Abrams GA, Bertics PJ, Murphy CJ, Nealey PF (2003) Epithelial contact guidance on welldefined micro- and nanostructured substrates. J Cell Sci 116: 1881-1892.

Van der Valk P, Van Pelt AWJ, Busscher HJ, De Jong HP, Wildevuur ChRH, Arends J (1983) Interaction of fibroblasts and polymer surfaces: relationship between surface free energy and fibroblast spreading. J Biomed Mater Res 17: 807-817.

Webb K, Hlady V, Tresco PA (1998) Relative importance of surface wettability and charged functional groups on NIH 3T3 fibroblast attachment, spreading, and cytoskeleton organization. J Biomed Mater Res 41: 422430 .

Webb K, Hlady V, Tresco PA (2000) Relationships among cell attachment, spreading, cytoskeletal organization, and migration rate for anchorage-dependent cells on model surfaces. J Biomed Mater Res 49: 362368 .

Wenzel RN (1936) Resistance of solid surfaces to wetting by water. Ind Eng Chem 28: 988-994.

Yang ZH, Chiu CY, Yang JT, Yeh JA (2009) Investigation and application of an ultrahydrophobic hybrid-structured surface with anti-sticking character. J Micromech Microeng 19: 085022.

Zhang X, Chattopadhyay A, Ji QS, Owen JD, Ruest PJ, Carpenter G, Hanks SK (1999) Focal adhesion kinase promotes phospholipase C-ã1 activity. Proc Natl Acad Sci USA 96: 9021-9026. 